Journal of Dairy Research

cambridge.org/dar

\section{Research Reflection}

Cite this article: Fagnani R, Nero LA and Rosolem CP (2021). Why knowledge is the best way to reduce the risks associated with raw milk and raw milk products. Journal of Dairy Research 88, 238-243. https://doi.org/10.1017/ S002202992100039X

Received: 15 June 2020

Revised: 16 February 2021

Accepted: 23 February 2021

First published online: 14 May 2021

\section{Keywords:}

Food safety; foodborne diseases; public health; raw milk

\section{Author for correspondence:}

Rafael Fagnani, Email: rafaelfagnani@hotmail. com

\title{
Why knowledge is the best way to reduce the risks associated with raw milk and raw milk products
}

\section{Rafael Fagnani ${ }^{1}$, Luis Augusto Nero ${ }^{2}$ and Carla Prado Rosolem ${ }^{1}$}

\footnotetext{
${ }^{1}$ Mestrado em Ciência e Tecnologia de Leite e Derivados, Universidade Pitágoras-Unopar, Londrina PR, Brazil and ${ }^{2}$ Universidade Federal de Viçosa, Departamento de Veterinária, InsPOA - Laboratório de Inspeção de Produtos de Origem Animal, Viçosa MG, Brazil
}

\begin{abstract}
In an age of flexible conditions about mandatory milk pasteurisation, this opinion-based research reflection supports the view that the knowledge and the awareness of milk-borne infections are key requirements to decrease the risks associated with raw milk. Providing an analysis of the current potential risks related to consumption of raw milk and raw milk products, we discuss the main reasons to continue to be vigilant about milk-borne pathogens and the current scenario in relation to the formal and clandestine sale of raw milk. Finally, we select some highly effective strategies to reduce the risks associated with raw milk in food services. Regardless of whether a country regulation allows or prohibits the trade of raw milk and its products, this is not the time to be negligent.
\end{abstract}

\section{Introduction}

Given that most dairy products are now industrialised, thermally treated and have to undergo sanitary inspection during processing, is it still necessary to be concerned about diseases related to consumption of dairy products? This issue is often discussed amongst food safety researchers and industry professionals, but it is not always possible to reach a consensus (O'Callaghan et al., 2019).

In a multitude of scientific articles (over 900000 Google Scholar search results typing 'raw milk consumption') it is possible to notice a remarkable convergence of ideas: the knowledge and the awareness of milk-borne infections are key requirements to decrease the risks associated with raw milk. The national regulations, the inspection service and the market surveillance are perennial strategies and cannot be neglected. However, food safety is only maximised when adopting simultaneous knowledge intensive practises. Here, we aim to clarify some relevant points related to dairy-borne diseases, providing information regarding the current scenario of the clandestine sale of raw milk and its products, in order to allow improvements in food safety.

\section{Current relevance of milk-borne pathogens}

There are three main reasons why it is still important to be aware about milk-borne pathogens. The first reason is because the sale of raw milk is regulated in some countries and direct sale to consumers is, therefore, possible. Raw milk is a product that has not undergone any thermal processing. Even milk from healthy cows, without any alterations, can still contain pathogenic microorganisms and transmit pathogens. Some of these diseases can be lethal, such as tuberculosis and listeriosis, whilst others may be incurable such as brucellosis (Claeys et al., 2013). In recent times, the consumption of bulk milk sold directly from producers was found to be associated with a higher probability of haemolytic uraemic syndrome (Ntuli et al., 2018). Thus, raw milk can pose a risk to public health.

In view of this concern, the pasteurisation of milk for direct human consumption and for the production of fresh cheese is mandatory in many countries, including Australia and Brazil (Baars, 2019). However, more flexible conditions are found in other countries, like USA, where some states allow the sale of raw milk, while others still prohibit such sales (Mungai et al., 2015). In some countries, such as the UK, the situation can be more permissive and raw milk can be sold directly to consumers. However, strategies in the UK to reduce risks are well established, and raw milk must be from official brucellosis and tuberculosis-free herds (Abernethy et al., 2013). In addition, such milk must carry a health warning and can only be sold by registered milk producers or by milk roundsmen.

Can such permissive behaviour have an impact on consumer health? Prior to the 1950s, about a quarter of all foodborne infections were associated to milk consumption. Following the introduction of regulations recommending milk pasteurisation, milk was attributed with less than 1\% of reported outbreaks of foodborne diseases (Mungai et al., 2015). However, 
in recent years this figure seems to be increasing as more countries have allowed the legal sale of raw milk. For example, in the USA the average number of outbreaks linked to raw milk each year was four times higher from 2007 to 2012 than from 1993 to 2006. Furthermore, the percentage of outbreaks associated with raw milk increased from $2 \%(2007-2009)$ to $5 \%$ (2010-2012) (Mungai et al., 2015). The infection risks associated with the consumption of raw milk are clear and undisputed; throughout history, mandatory pasteurisation has been linked with decreased numbers of outbreaks of milk-borne pathogens (Alegbeleye et al., 2018).

The second reason to continue to be vigilant about milk-borne pathogens is that even where governments restrict legal sales, raw milk and its products can be purchased clandestinely, such as in street markets or from roundsmen (Paraffin et al., 2018). Compared to places where the sale of raw milk is regulated, the clandestine market poses more risks to public health because such locations are not checked by official inspection agents. In such locations there is no guarantee of food safety. In addition to the diseases that can be transmitted, these products may also be fraudulent (Tibola et al., 2018). These frauds are economically motivated and may breach the rights of consumers regarding the authentic purchasing of dairy products. Examples of this include adding water to increase volume and chemicals to preserve their shelf life, selling milk as belonging from one species when it is actually produced by another, adding non-dairy fats, and so on (Tibola et al., 2018). Consequently, clandestine dairy products are highly likely to be adulterated

The third reason to continue to be aware of milk-borne pathogens relates to the consumers themselves. Why do consumers continue to buy these products? Is it due to a lack of information? Because of the flavour? A lack of choice? The price? A mistrust of industrialised products? The most commonly cited motivations behind the consumption of clandestine dairy products are the taste and the purity of such products (Buzby et al., 2013; Raymundo et al., 2018; Waldman and Kerr, 2018). However, the motivations that might drive European are not necessarily the same as for Americans, but are strongly influenced by culture. Socio-cultural aspects, such as regulatory history, cultural norms, socio-economic status, perception of health and risk and even social justice, also contribute to individual and population preferences regarding raw milk consumption (Meunier-Goddik and Waite-Cusic, 2019).

There has been much popular discussion about the risks and benefits derived from the consumption of raw milk, but all current scientific studies and reviews have categorically concluded that there is no evidence that raw milk has any inherent health or nutritional benefits that outweigh the risks associated with its consumption (Macdonald et al., 2011). Thus the idea that raw milk might be a super food is misplaced (Alegbeleye et al., 2018).

It should be stressed that consumers receive information and make purchasing decisions based on non-scientific criteria, without consideration for factors such as safety and risk (Jay-Russell, 2010). In a recent study, about $17 \%$ of raw milk samples tested positive for antibiotic residues, and over $21 \%$ were found to be adulterated with water, which contradicts the concept that clandestine raw milk is pure and without chemical modifications (Ondieki et al., 2017).

\section{Main threats associated with raw milk and its products}

The consumption of raw milk and its products may pose risks to the health of those who consume them, so much so that warning labels are required on raw milk sold in some countries such as UK and some U.S states, such as California. However, what are the risks of using raw milk and its products as ingredients in thermally processed food, such as bread, cookies, cakes and other baked goods? If milk and its products are obtained from the clandestine market, then the hazards and risks are those mentioned above. These issues can result in low quality products, low yields, microbiological fermentation failures due to possible antibiotic residues and taste defects (Fleischer et al., 2001; Novés et al., 2015). These taste defects may be of microbiological origin, caused by bacteria that produce proteolytic and lipolytic enzymes, and/or physical factors such as oxidative rancidity caused by exposure to light (Cadwallader and Singh, 2009).

If raw milk and its products are obtained from the formal market, then the problem of adulteration is minimised. However, there will still be microbiological risks. As an example, a monitoring survey of raw milk sold through vending machines in Italy from 2009 to 2011 found that of the 618 samples tested, $1.6 \%$ were positive for Listeria monocytogens, $1.5 \%$ for Campylobacter spp., $0.3 \%$ for Salmonella spp. and $0.2 \%$ for E. coli $\mathrm{O} 157$ (Bianchi et al., 2013). It is important to highlight that all samples came from health and vaccinated herds and the selling vending machines were in accordance with the enactment of an Italian law that allows the sale of unpacked and unpasteurised cows milk on the farm and at markets. More recently (2016), an outbreak with 69 cases of campylobacteriosis was linked with raw milk from vending machines in England (Kenyon et al., 2020). These findings raise the question of whether some national regimes for unpasteurised milk are fit for purpose.

Due to the influence of the food matrix on the viability of bacterial pathogens, the dairy products most commonly involved in milk-borne infections are raw milk, fresh cheeses (without maturation) and fatty products such as cream and butter (Fox et al., 2018). Despite the fact that most cooked foods usually uses temperatures higher than $180^{\circ} \mathrm{C}$ there are still three basic threats: staphylococcal enterotoxins, Brucella spp. and cross contamination. Figure 1 summarises the main health risks associated with raw and dairy products.

\section{Staphylococcal enterotoxins}

The vegetative cells of all pathogenic microorganisms are completely inactivated during pasteurisation. Various times and temperatures can be used to ensure safety, the most common being $72-75^{\circ} \mathrm{C}$ for $15-20 \mathrm{~s}$ or $62-65^{\circ} \mathrm{C}$ for $30 \mathrm{~min}$. Boiling raw milk ensures the safety of the product from this point of view (Tremonte et al., 2014). The remaining problem lies in the presence of staphylococcal enterotoxins, that are resistant to boiling and pasteurisation. They are only inactivated at 120 psi for twenty minutes, and this condition can only be achieved using autoclaves. When ingested, staphylococcal entorotoxins cause staphylococcal gastroenteritis, a rapidly evolving type of food poisoning (from thirty minutes to six hours after the ingestion of contaminated food), as well as clinical symptoms of nausea, vomiting, headaches, abdominal pain and diarrhoea (Artursson et al., 2018; Suzuki, 2019).

\section{Brucella spp.}

Cream and whipped cream are widely used in food services, whether for making Chantilly, to cover cakes, in ice cream, for creamy fillings, etc. Cows, goats and sheep that are infected 
Fig. 1. Main threats associated with raw milk and its products and effective guidance strategies to reduce them.

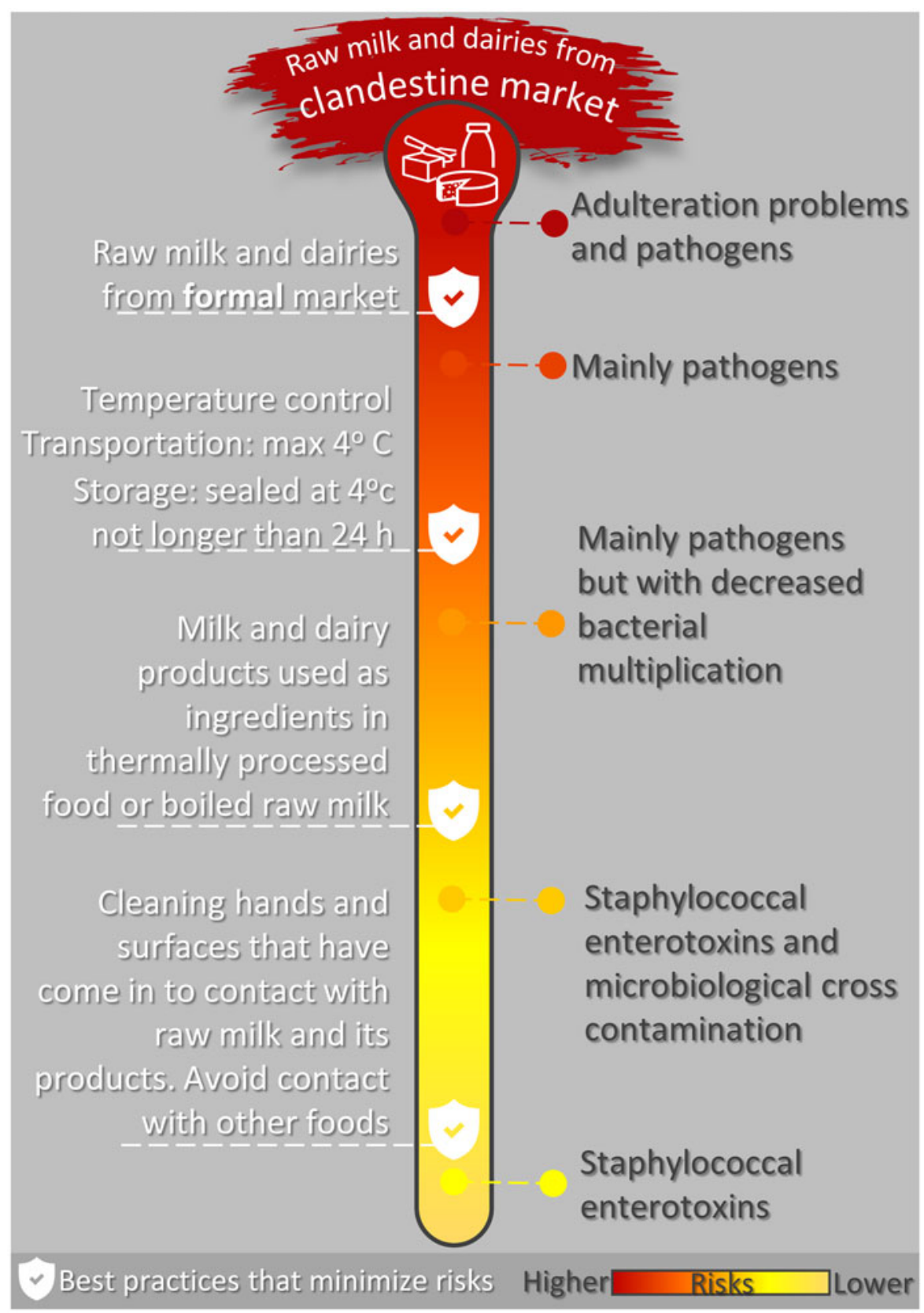

with brucellosis excrete Brucella cells in farmed milk with no visible alterations (LeJeune and Rajala-Schultz, 2009). These microorganisms have an affinity for milk fat globules, and the dairy derivatives that pose the greatest risk are cream and whipped cream. The higher the level of fat, the greater the risk of transmission. This problem is enhanced because the cream is not usually baked with the dough, resulting in the continuing presence of viable cells in these products (Kaden et al., 2018). Brucellosis is an incurable chronic disease that causes arthritis, meningitis, endocarditis, orchitis, fevers and night chills (Doganay and Aygen, 2003).

\section{Cross-contamination}

This threat is related to failures in the food safety procedures and may only occur when a pathogenic microorganism is present. In this case, raw milk and its products can be sources of contamination in food services and industrial kitchens. Some pathogenic cells, such as L. monocytogenes, can spread to all surfaces through cross-contamination. The frequency of this microorganism in milk is considerable: of 861 samples of raw milk, almost 7\% contained L. monocytogenes (Van Kessel et al., 2004). Furthermore, this microorganism has adapted to stainless steel surfaces, where it can set and form biofilms (Herald and Zottola, 1988; Oliveira et al., 2010). Even in industrial plants with excellent levels of cleaning the occurrence of L. monocytogenes is 7\%; in places where cleaning is deficient the occurrence can reach almost $28 \%$ (Walker et al., 1991). Listeriosis is a disease of high mortality but low morbidity: immunosuppressed people are most affected. In addition to causing death, listeriosis also causes miscarriages, arthritis and encephalitis; in its non-invasive form it can result in gastroenteritis. 
Another aetiological agent of foodborne diseases linked to dairy products is Campylobacter jejuni (Paramithiotis et al., 2017). Over the past decade this pathogenic bacterium has been detected worldwide in raw milk. Recently, almost $12 \%$ of raw milk purchased from individual suppliers were positive in Poland (Andrzejewska et al., 2019). In New Zealand, Campylobacter is the most common pathogen reported in association with raw milk-related disease outbreaks (Davys et al., 2020). The primary reason is the use of unpasteurised milk for the production of dairy products (Paramithiotis et al., 2017).

Although pasteurisation can effectively eliminate vegetative cells (including C. jejuni) (Murphy et al., 2003), it should not be regarded as the only line of defence, especially since the contamination may occur during the subsequent processing steps. One of the consequences of cross-contamination is the growing number of recalls of dairy products, increasing from $4 \%$ (in 2015) to $17 \%$ in USA (2017) (Paramithiotis et al., 2017).

\section{Reducing the risks associated with raw milk in food services}

In order to reduce the risks associated with raw milk and its products, there are five highly effective guidance strategies for food services: (1) Never buy milk and its derivatives from clandestine sources; the latter are not inspected, and in addition to transmitting pathogens these products may be adulterated; (2) When buying raw milk from legally approved sources always boil the raw milk before use or consumption, once even inspected raw products can harbour pathogenic bacteria. (3) Fatty dairy products pose considerable risks: only use industrialised cream, whipped cream and butter; (4) Clean hands and surfaces that have come into contact with raw milk and its products to minimise crosscontamination: hands and surfaces should be cleaned with soap and water and then sanitised; (5) It is essential to strictly control the temperature regarding raw milk and its products; this practice is not only linked to spoilage bacteria, but it can also minimise the presence of pathogenic microorganisms (Leclair et al., 2019). The temperature of transport and refrigeration should never exceed $4{ }^{\circ} \mathrm{C}$. Use recyclable ice and thermal containers during transport. Do not use products stored for more than $24 \mathrm{~h}$, even if refrigerated at $4^{\circ} \mathrm{C}$. Products should be sealed when stored, should not come into contact with other foods, and should be consumed as soon as possible. Freezing does not guarantee safety: some microorganisms such as L. monocytogenes can survive for more than $365 \mathrm{~d}$ in frozen raw milk (Leclair et al., 2019). Figure 1 summarises the main strategies discussed above.

However, knowledge is the best way to reduce the risks associated with raw milk and its products. A recent study concluded that the ability to understand the risks associated with the consumption of unpasteurised dairy products was linked to the health status of the population. We found that consumers who are aware of milkborne pathogens were twice as likely not to have abdominal pain. For the first time, it was observed that the awareness of milk-borne pathogens provides benefits for consumer health and is a protective factor in relation to abdominal pain (Fagnani et al., 2019).

Other examples also show a positive association between general knowledge and health status. Mosalagae et al. (2011) stated that by improving the level of awareness for zoonoses, teaching and training of population, both human health and food safety could be enhanced. In addition, Bell et al. (1999) also concluded that educational workshops were a successful food safety intervention to reduce the incidence of Salmonella Typhimurium associated with eating fresh cheese. This leads us to reinforce that knowledge can promote health-seeking behaviour and good health, as reported by Aaby et al. (2017).

More recently, a study conducted in Tanzania evaluated how narrative and technical risk and health messages impacted the hygiene practices and the milk quality in a pastoral community (Caudell et al., 2019). The results suggest that the use of narrative messages can promote healthy behaviour even when cultural norms are contrary to best health practices (Caudell et al., 2019). In low income and/or developing countries there is a strong association between educational level and the knowledge of the population on milk borne zoonosis (Mandefero and Yeshibelay, 2018). These regions face challenges to increase the educational level of the whole population, and consequently reduce the incidence of diseases assocaited with raw milk consumption (Kumar et al., 2017). However, it is common to find people aware of the raw milk consumption risks in developed countries, but still consuming raw milk. Here, the challenge is not only to increase the awareness about milk-borne infections, but to understand why the health risks are ignored by this segment of the population. Then, the strategies to promote knowledge should be in line with the demographic condition. Not only milk-borne diseases but any dietary-related condition are more easily preventable if consumers understand the factors that support their dietary choices.

Regardless of whether a country regulation allows or prohibits the trade of raw milk and its products, knowledge of the risks associated with these products is critical to assure the population health. Consumers should be kept informed and alerted regarding this issue, whether via product labels, through advertising campaigns promoted by official inspection and regulatory offices or via university outreach programmes. In addition, it is clear that this is not the time to be negligent regarding raw milk and its products because of the health risks that they represent, especially those that are purchased clandestinely.

\section{Future progress}

As in other areas, knowledge is the key to promoting health. But how to achieve it? Traditionally, it can be achieved by ongoing and continuous training of food handlers. Each food sector should develop specific didactic and pedagogical techniques providing realistic examples (Gomes et al., 2014). Not least, teaching and training of the population is also essential to strengthen awareness for better food safety. But first, studies about the demographics, perceptions and behavioural attributes of consumers can be helpful in targeting educational efforts and better strategies on consumer education.

In the absence of massive scientific dissemination in this area, it is very likely that distorted information can be spread easily through the population, mainly through the web and social media platforms. However, false information would be ineffective if readers were able to identify it as such. Thus, the exteriorisation of regulations, science and technology out of its own sphere of production is a key requirement for better food safety. The university, organised civil societies, and mainly the government, can bridge the gap between trusted information and society at large through scientific dissemination to ensure a better understanding of food safety (Zhu et al., 2019).

Acknowledgements. This research did not receive any specific grant from funding agencies in the public, commercial, or not-for-profit sectors. 


\section{References}

Aaby A, Friis K, Christensen B, Rowlands G and Maindal HT (2017) Health literacy is associated with health behaviour and self-reported health: a large population-based study in individuals with cardiovascular disease. European Journal of Preventative Cardiology 24, 1880-1888.

Abernethy DA, Upton P, Higgins IM, McGrath G, Goodchild AV, Rolfe SJ, Broughan JM, Downs SH, Clifton-Hadley R, Menzies FD, de la Rua-Domenech R, Blissitt MJ, Duignan A and More SJ (2013) Bovine tuberculosis trends in the UK and the Republic of Ireland, 1995-2010. Veterinary Record 172, 312-312.

Alegbeleye OO, Guimarães JT, Cruz AG and Sant'Ana AS (2018) Hazards of a 'healthy' trend? An appraisal of the risks of raw milk consumption and the potential of novel treatment technologies to serve as alternatives to pasteurization. Trends in Food Science and Technology 82, 148-166.

Andrzejewska M, Szczepańska B, Śpica D and Klawe JJ (2019) Prevalence, virulence, and antimicrobial resistance of Campylobacter spp. in raw milk, beef, and pork meat in Northern Poland. Foods (basel, Switzerland) 8, 420.

Artursson K, Schelin J, Thisted Lambertz S, Hansson I and Olsson Engvall E (2018) Foodborne pathogens in unpasteurized milk in Sweden. International Journal of Food Microbiology 284, 120-127.

Baars T (2019) Chapter 4. Regulations and production of raw milk. In Nero LA and de Carvalho AF (eds), Raw Milk Balance Between Hazards and Benefits. Cambridge, Massachusetts: Academic Press, Elsevier, pp. 65-89.

Bell RA, Hillers VN and Thomas TA (1999) The Abuela project: safe cheese workshops to reduce the incidence of Salmonella typhimurium from consumption of raw-milk fresh cheese. American Journal of Public Health 89, 1421-1424.

Bianchi DM, Barbaro A, Gallina S, Vitale N, Chiavacci L, Caramelli M and Decastelli L (2013) Monitoring of foodborne pathogenic bacteria in vending machine raw milk in Piedmont, Italy. Food Control 32, 435-439.

Buzby JC, Hannah Gould L, Kendall ME, Jones TF, Robinson T and Blayney DP (2013) Characteristics of consumers of unpasteurized milk in the United States. Journal of Consumers Affair 47, 153-166.

Cadwallader KR and Singh TK (2009) Chapter flavours and off-flavours in milk and dairy products. In McSweeney P and Fox P (eds), Advanced Dairy Chemistry. New York, NY: Springer New York, pp. 631-690.

Caudell MA, Charoonsophonsak PV, Miller A, Lyimo B, Subbiah M, Buza J and Call DR (2019) Narrative risk messages increase uptake and sharing of health interventions in a hard-to-reach population: a pilot study to promote milk safety among Maasai pastoralists in Tanzania. Pastoralism 9, 1-12.

Claeys WL, Cardoen S, Daube G, De Block J, Dewettinck K, Dierick K, De Zutter $L$, Huyghebaert A, Imberechts $H$, Thiange $P$, Vandenplas $Y$ and Herman L (2013) Raw or heated cow milk consumption: review of risks and benefits. Food Control 31, 251-262.

Davys G, Marshall JC, Fayaz A, Weir RP and Benschop J (2020) Campylobacteriosis associated with the consumption of unpasteurised milk: findings from a sentinel surveillance site. Epidemiology and Infection 148, 1-10.

Doganay M and Aygen B (2003) Human brucellosis: an overview. International Journal of Infectious Disease 7, 173-182.

Fagnani R, Eleodoro JI and Zanon EO (2019) Milk-borne infections awareness and the health status of consumers: an on-line survey. International Dairy Journal 96, 85-92.

Fleischer P, Metzner M, Beyerbach M, Hoedemaker M and Klee W (2001) The relationship between milk yield and the incidence of some diseases in dairy cows. Journal of Dairy Science 84, 2025-2035.

Fox EM, Jiang Y and Gobius KS (2018) Key pathogenic bacteria associated with dairy foods: on-farm ecology and products associated with foodborne pathogen transmission. International Dairy Journal 84, 28-35.

Gomes CCB, Lemos GFC, Silva MC, Hora IMC and Cruz AG (2014) Training of food handlers in a hotel: tool for promotion of the food safety. Journal of Food Safety 34, 218-223.

Herald PJ and Zottola EA (1988) Attachment of Listeria monocytogenes to stainless steel surfaces at various temperatures and $\mathrm{pH}$ values. Journal of Food Science 53, 1549-1562.

Jay-Russell MT (2010) Raw (unpasteurized) milk: are health-conscious consumers making an unhealthy choice? Clinical Infectious Diseases 51, 14181419.
Kaden R, Ferrari S, Jinnerot T, Lindberg $M$, Wahab $T$ and Lavander $M$ (2018) Brucella abortus: determination of survival times and evaluation of methods for detection in several matrices. BMC Infectious Diseases 18, 1-6.

Kenyon J, Inns T, Aird H, Swift C, Astbury J, Forester E and Decraene V (2020) Campylobacter outbreak associated with raw drinking milk, North West England, 2016. Epidemiology and Infection 148, 1-13.

Kumar SD, Dahia SP, Yadav AS, Kumar S and Tomar P (2017) Milk borne zoonoses: public health concern: a review. Indian Journal of Health and Well-Being 8, 1079-1082.

Leclair RM, McLean SK, Dunn LA, Meyer D and Palombo EA (2019) Investigating the effects of time and temperature on the growth of Escherichia coli O157: H7 and Listeria monocytogenes in raw cow's milk based on simulated consumer food handling practices. International Journal of Environmental Research and Public Health 16, 1-11.

LeJeune JT and Rajala-Schultz PJ (2009) Unpasteurized milk: a continued public health threat. Clinical and Infectious Disease 48, 93-100.

Macdonald LE, Brett J, Kelton D, Majowicz SE, Snedeker K and Sargeant JM (2011) A systematic review and meta-analysis of the effects of pasteurization on milk vitamins, and evidence for raw milk consumption and other health-related outcomes. Journal of Food Protection 74, 1814-1832.

Mandefero D and Yeshibelay G (2018) Assessment of community knowledge, attitude and practice on milk borne zoonoses disease in Debre-Birhan town, north Shewa, Ethiopia. Journal of Public Health and Epidemiology 10, 123-131.

Meunier-Goddik L and Waite-Cusic J (2019) Chapter 15. Consumers acceptance of raw milk and its products. In Nero LA and de Carvalho AF (eds), Raw Milk Balance Between Hazards and Benefits. Cambridge, Massachusetts: Academic Press, Elsevier, pp. 311-350.

Mosalagae D, Pfukenyi DM and Matope G (2011) Milk producers' awareness of milk-borne zoonoses in selected smallholder and commercial dairy farms of Zimbabwe. Tropical Animal Health Production 43, 733-739.

Mungai EA, Behravesh CB and Gould LH (2015) Increased outbreaks associated with nonpasteurized milk, United States, 2007-2012. Emerging Infectious Diseases 21, 119-122.

Murphy C, Carroll C and Jordan KN (2003) Identification of a novel stress resistance mechanism in Campylobacter jejuni. Journal of Applied Microbiology 95, 704-708.

Novés B, Librán C, Licón CC, Molina MP, Molina A and Berruga MI (2015) Technological failures caused by cephalexin in set-type sheeps milk yogurt. CYTA - Journal of Food 13, 408-414.

Ntuli V, Njage PMK, Bonilauri P, Serraino A and Buys EM (2018) Quantitative risk assessment of hemolytic uremic syndrome associated with consumption of bulk milk sold directly from producer to consumer in South Africa. Journal of Food Protection 81, 472-481.

O'Callaghan TF, Sugrue I, Hill C, Ross RP and Stanton C (2019) Chapter 7. Nutritional aspects of raw milk: a beneficial or hazardous food choice. In Nero LA and de Carvalho AF (eds), Raw Milk Balance Between Hazards and Benefits. Cambridge, Massachusetts: Academic Press, Elsevier, pp. 127-148.

Oliveira MMM, de Brugnera DF, Alves E and Piccoli RH (2010) Biofilm formation by Listeria monocytogenes on stainless steel surface and biotransfer potential. Brazilian Journal of Microbiology 41, 97-106.

Ondieki GK, Ombui JN, Obonyo M, Gura Z, Githuku J, Orinde AB and Gikunju JK (2017) Antimicrobial residues and compositional quality of informally marketed raw cow milk, Lamu West Sub-County, Kenya, 2015. The Pan African Medical Journal 28, 1-6.

Paraffin AS, Zindove TJ and Chimonyo M (2018) Household consumption preferences of dairy products and their perceptions of milk safety. Journal of Food Safety 38, 1-8.

Paramithiotis S, Drosinos EH and Skandamis PN (2017) Food recalls and warnings due to the presence of foodborne pathogens - a focus on fresh fruits, vegetables, dairy and eggs. Current Opinion on Food Science 18, 71-75.

Raymundo NKL, Bersot L dos S and Osaki SC (2018) Consumer profile and problems associated with uninspected raw milk consumption in western Paraná. Arquivos do Instituto Biológico 84, 1-8.

Suzuki Y (2019) Current studies of staphylococcal food poisoning. Journal of the Food Hygienic Society of Japan 60, 27-37.

Tibola CS, da Silva SA, Dossa AA and Patrício DI (2018) Economically motivated food fraud and adulteration in Brazil: incidents and alternatives to minimize occurrence. Journal of Food Science 83, 2028-2038. 
Tremonte P, Tipaldi L, Succi M, Pannella G, Falasca L, Capilongo V, Coppola R and Sorrentino E (2014) Raw milk from vending machines: effects of boiling, microwave treatment, and refrigeration on microbiological quality. Journal of Dairy Science 97, 3314-3320.

Van Kessel JS, Karns JS, Gorski L, McCluskey BJ and Perdue ML (2004) Prevalence of Salmonellae, Listeria monocytogenes, and fecal coliforms in bulk tank milk on US dairies. Journal of Dairy Science 87, 2822-2830.
Waldman KB and Kerr JM (2018) Does safety information influence consumers' preferences for controversial food products? Food Quality and Preference 64, 56-65.

Walker RL, Jensen LH, Kinde H, Alexander AV and Owens LS (1991) Environmental survey for Listeria Species in Frozen milk product plants in California. Journal of Food Protection 54, 178-182.

Zhu X, Yuelu Huang I and Manning L (2019) The role of media reporting in food safety governance in China: a dairy case study. Food Control 96, 165-179. 